\title{
Antibodies to citrullinated human fibrinogen (ACF) have diagnostic and prognostic value in early arthritis
}

\author{
M M J Nielen, A R van der Horst, D van Schaardenburg, I E van der Horst-Bruinsma, \\ R J van de Stadt, L Aarden, B A C Dijkmans, D Hamann
}

Ann Rheum Dis 2005;64:1199-1204. doi: 10.1136/ard.2004.029389

See end of article for authors' affiliations

Correspondence to: Dörte Hamann, Sanquin Diagnostic Services at CLB, Dept. of Autoimmune Diseases, Plesmanlaan 125, $1066 \mathrm{CX}$ Amsterdam, Netherlands; d.hamann@sanquin.nl

Accepted 2 January 2005 Published Online first 7 January 2005
Background: The anti-cyclic citrullinated peptide (CCP) test has a high sensitivity and specificity for rheumatoid arthritis, although CCP is not the physiological target of the autoantibodies. Citrullinated fibrin is abundant in inflamed synovium

Objective: To assess the diagnostic and prognostic value of antibodies against citrullinated fibrinogen (ACF), a soluble precursor of fibrin, in comparison with lgM-rheumatoid factor (IgM-RF) and the second generation anti-CCP test.

Methods: In 379 patients with early arthritis (258 rheumatoid and 121 undifferentiated), the sensitivity, specificity, and positive predictive value of $A C F$, anti-CCP, and IgM-RF for diagnosing rheumatoid arthritis were calculated. Multivariate logistic regression analysis was used to assess the diagnostic and prognostic value (radiographic progression after two years) of the tests.

Results: The sensitivities of the ACF, anti-CCP, and lgM-RF tests were $55.8 \%, 57.8 \%$, and $44.6 \%$, with specificities of $92.6 \%, 94.2 \%$, and $96.7 \%$, respectively. Approximately $30 \%$ of the IgM-RF negative patients were positive for ACF or anti-CCP or both. The ACF and anti-CCP test had a high agreement in early arthritis $(\kappa=0.84)$. Of all baseline characteristics, the ACF test and the anti-CCP test were the best predictors for diagnosing rheumatoid arthritis at one year (odds ratio $(O R)=10.3$ and 10.6, respectively) and for radiographic progression after two years $(O R=12.1$ and 14.8).

Conclusions: ACF is as sensitive as anti-CCP and more sensitive than IgM-RF in diagnosing rheumatoid arthritis in early arthritis. The ACF test is also a good predictor of radiographic progression, with a performance similar to the anti-CCP test. The ACF test and the anti-CCP test are especially valuable in lgMRF negative arthritis.
$\mathrm{R}$ heumatoid arthritis is a systemic autoimmune disease of unknown origin. To prevent joint destruction, early diagnosis and treatment is required. The diagnosis can be made by the 1987 classification criteria of the American College of Rheumatology (ACR), ${ }^{1}$ but these criteria have a low sensitivity in early arthritis. ${ }^{2}$

There are a few rheumatoid arthritis specific antibodies. These include the so called antiperinuclear factor (APF), antifilaggrin antibodies (AFA), and antikeratin antibodies (AKA). The epitopes recognised by APF, AFA, and AKA were found to be generated by a post-translational modificationnamely deimination of the natural amino acid arginine to the amino acid citrulline by activity of peptidylarginine deiminase. ${ }^{3}$ Based on that knowledge, Schellekens and co-workers developed an enzyme linked immunosorbent assay (ELISA) using a cyclic citrullinated peptide (CCP) derived from the sequence of human filaggrin as substrate. ${ }^{4}$ The assay was later improved (the second generation anti-CCP test) and sensitivities of $70-80 \%$ at specificities of $98-99 \%$ have been reported in established rheumatoid arthritis and controls. ${ }^{56}$ Sensitivity in early arthritis cohorts for the diagnosis rheumatoid arthritis varies between $40 \%$ and $70 \% .{ }^{4-11}$ Although the anti-CCP ELISA has a reasonable sensitivity, the cyclic citrullinated peptide is not the physiological target of the autoantibodies.

Citrulline containing antigens are expressed in rheumatoid arthritis synovium. ${ }^{12}{ }^{13}$ Moreover, B cells that actively secrete anti-CCP are specifically present in bone marrow and synovial fluid of anti-CCP seropositive patients with rheu- matoid arthritis. ${ }^{14} 15$ When searching for the nature of citrullinated proteins in rheumatoid synovial tissue, Masson-Bessière et al identified citrullinated $\alpha$ and $\beta$ chains of fibrin as the target for APF, AFA, or AKA positive sera. ${ }^{16}$ Subsequently, antibodies to in vitro citrullinated fibrinogen, a soluble precursor of fibrin, have been described as a serological criterion for the early diagnosis of rheumatoid arthritis when compared with rheumatoid factor (RF) and the first generation anti-CCP assay. ${ }^{17}$

To study the diagnostic and prognostic value of anticitrullinated fibrinogen (ACF) in early arthritis in comparison with IgM-RF and the second generation anti-CCP test, two studies were undertaken: a cross sectional analysis of patients with established rheumatoid arthritis and nonrheumatoid controls, and a diagnostic and prognostic study on patients from an early arthritis clinic (EAC).

\section{METHODS \\ Patients}

To calculate the cut off values of the ACF test, anti-CCP test, and the IgM-RF test at $99 \%$ specificity, the following groups of patients were tested: 239 established cases of rheumatoid

Abbreviations: $A C F$, antibodies to citrullinated human fibrinogen; $A C R$, American College of Rheumatology; AFA, anti-filaggrin antibodies; AKA, antikeratin antibodies; APF, antiperinuclear factor; $C C P$, cyclic citrullinated peptide; DAS28, 28 joint disease activity score; DMARD, disease modifying anti-rheumatic drug; $E A C$, early arthritis clinic; $H A Q$, health assessment questionnaire; RF, rheumatoid factor; ROC, receiver operating characteristic; VAS, visual analogue scale 
arthritis (53 active and 186 in clinical remission), 91 rheumatology clinic patients without arthritis, and 91 healthy controls. The rheumatoid patients fulfilled the ACR criteria for rheumatoid arthritis. ${ }^{1}$ These calculated cut off values were then used to study the diagnostic and prognostic value of the ACF test in comparison with the IgM-RF and anti-CCP tests in a study population.

This study population consisted of 379 consecutive patients aged $\geqslant 18$ years, with peripheral arthritis of two or more joints and a symptom duration of two years or more; they were referred to the EAC of the Jan van Breemen Institute, a large rheumatology clinic in Amsterdam, between 1995 and 1998. Patients who had previously been treated with a disease modifying anti-rheumatic drug (DMARD) and those with spondylarthropathy, reactive arthritis, crystal induced arthropathy, systemic lupus erythematosus, Sjögren's syndrome, or osteoarthritis were excluded. The diagnosis of rheumatoid arthritis after one year follow up was made in 258 patients by an experienced rheumatologist (BD), who was blinded to the results of the ACF and anti-CCP tests. The remaining 121 non-rheumatoid patients were classified as having undifferentiated arthritis (73 with polyarthritis and 48 with oligoarthritis).

\section{Disease indices}

The following data were collected during the first visit: demographic characteristics, disease duration, disease activity by disease activity score (DAS28), ${ }^{18}$ pain by visual analogue scale (VAS), and functional status by the health assessment questionnaire (HAQ) ${ }^{19}$ Laboratory assessments at baseline included erythrocyte sedimentation rate (ESR), C reactive protein, IgM-RF, ACF, and anti-CCP. Radiographs of hands and feet were obtained at baseline and after two years. The number of erosions and the joint space narrowing were scored according to the Sharp/van der Heijde method ${ }^{20}$ by an experienced rheumatologist (DvS), who was blinded to all baseline variables.

\section{Antibody measurements}

Antibodies to CCP were measured using the second generation immunoscan rheumatoid arthritis ELISA kit (Eurodiagnostica, Arnhem, Netherlands, cut off value $25 \mathrm{AU} / \mathrm{ml}$ ). The assay was carried out according to the manufacturer's protocol. IgM-RF was measured on an ES300 immunochemistry analyser (Roche Diagnostics, Almere, Netherlands) as described before. ${ }^{10}$

IgG antibodies to citrullinated fibrinogen were detected by ELISA using citrullinated fibrinogen as immunosorbent. ${ }^{17}$ Plasminogen-free fibrinogen (Calbiochem, Breda, Netherlands) was depleted of IgG using protein G sepharose. IgG-free fibrinogen was citrullinated in vitro using rabbit skeletal muscle peptidylarginine deiminase (PAD) (Sigma, Zwijndrecht, Netherlands): $7 \mathrm{U} / \mathrm{mg}$ fibrinogen in $0.1 \mathrm{M}$ Tris$\mathrm{HCl}\left(\mathrm{pH} \mathrm{7.4)}, 10 \mathrm{mM} \mathrm{CaCl}_{2}\right.$, and $5 \mathrm{mM}$ DTT for two hours at $37^{\circ} \mathrm{C} .{ }^{21}$ Citrullination was controlled by a mobility shift of $\alpha$ and $\beta$ chain of fibrinogen detected by SDS gel electrophoresis followed by western blotting with a positive serum. ${ }^{16}$ Microtitre plates (MaxiSorp, Nunc, Roskilde, Denmark) coated with citrullinated fibrinogen $(10 \mu \mathrm{g} / \mathrm{ml}$ phosphate buffered saline (PBS)) were incubated for one hour at room temperature with diluted sera in duplicate ( $1: 50$ in PBS, $0.2 \%$ gelatine, $0.05 \%$ ( $\mathrm{vol} / \mathrm{vol}$ ) Tween 20). After incubation with horseradish peroxidase conjugated mouse monoclonal antihuman IgG (MH16MIXME, Sanquin, Amsterdam, Netherlands) for one hour at room temperature, 3,3',5,5' tetramethylbenzidine $(10 \mathrm{mg} / \mathrm{ml}$ in DMSO) $1: 100$ diluted in $0.11 \mathrm{M}$ acetate buffer $\mathrm{pH} 5.5$ supplemented with $10 \mu \mathrm{l} / 10 \mathrm{ml}$ of a $3 \% \mathrm{H}_{2} \mathrm{O}_{2}$ solution was added. The reaction was stopped with $2 \mathrm{M} \mathrm{H}_{2} \mathrm{SO}_{4}$ and absorbance at $450 \mathrm{~nm}$ was measured. All washing steps were carried out with PBS, $0.1 \%$ Tween 20 . The antibody titre is expressed in AU/ml using a pool of IgM-RF positive sera as calibrator in eight dilutions. Coefficients of intra-assay and interassay variation were below $20 \%$ both for the same batch of citrullinated fibrinogen and for different batches.

Nissinen et al reported that a majority of patients with recent onset rheumatoid arthritis and 44\% of SLE patients were positive in an anti-PAD ELISA.22 Because the PAD enzyme used to citrullinate fibrinogen is not removed from the antigen preparation, antibodies to PAD might influence the results. This is, however, unlikely, as we did not find positive reactions with SLE sera.

\section{Data analysis}

First, in the group of established rheumatoid arthritis patients and controls, the area under the receiver operating characteristic (ROC) curve of ACF, anti-CCP, and IgM-RF was calculated and the sensitivities of the tests were compared at three specificities (95\%, 98.5\%, and 99\%). The cut off value of the three tests was calculated at $99 \%$ specificity. These values were used in the other statistical analyses.

Second, sensitivity, specificity, and positive predictive value (PPV) of ACF, anti-CCP, and IgM-RF were calculated in the group of 379 early arthritis patients. Sensitivity expresses the percentage of rheumatoid patients positive for the test, while specificity is calculated from the percentage of test negative patients with undifferentiated arthritis. The baseline characteristics of the rheumatoid patients and the patients with undifferentiated arthritis were compared using Student's $t$ test, the Mann-Whitney $U$ test, and the $\chi^{2}$ test, as appropriate.

Finally, multivariate logistic regression analysis was used to assess the diagnostic and prognostic value of the ACF test in patients with early arthritis. The diagnostic value of the test was assessed by predicting the diagnosis of rheumatoid arthritis or undifferentiated arthritis at a one year follow up, while the prognostic value was assessed by predicting radiographic progression at two years of follow up. Radiographic progression was defined as an increase in the

Table 1 Sensitivity of IgM-RF, anti-CCP, and ACF in patients with established rheumatoid arthritis and controls

\begin{tabular}{|c|c|c|c|c|c|}
\hline \multirow[b]{2}{*}{ Test } & \multicolumn{3}{|c|}{ Specificity } & \multirow{2}{*}{$\begin{array}{l}\text { Area under ROC } \\
\text { curve }\end{array}$} & \multirow[b]{2}{*}{ Confidence interval } \\
\hline & $95 \%$ & $98.5 \%$ & $99 \%$ & & \\
\hline $\lg M-R F$ & $49.8 \%$ & $45.2 \%$ & $41.8 \% \dagger$ & 0.726 & 0.678 to 0.774 \\
\hline Anti-CCP & $72.0 \%$ & $71.1 \%$ & $71.1 \% \ddagger$ & 0.903 & 0.873 to $0.932^{*}$ \\
\hline ACF & $72.4 \%$ & $67.8 \%$ & $67.8 \% \S$ & 0.893 & 0.861 to $0.925^{*}$ \\
\hline
\end{tabular}

${ }^{*} \mathrm{p}<0.05 v \lg M-R F$

Cut off values of the tests: †lgM-RF, $45 \mathrm{IU} / \mathrm{ml}$; łanti-CCP, $25 \mathrm{U} / \mathrm{ml} ; \S A C F, 140 \mathrm{U} / \mathrm{ml}$.

$A C F$, antibodies to citrullinated human fibrinogen; $C C P$, cyclic citrullinated peptide; RF, rheumatoid factor; ROC receiver operating characteristic. 
Table 2 Baseline characteristics of the early arthritis population, separated into rheumatoid arthritis (RA) and undifferentiated arthritis (UA)

\begin{tabular}{|c|c|c|c|c|}
\hline Baseline characteristics & Total group $(n=379)$ & RA (n= 258) & UA $(n=121)$ & p Value \\
\hline Age (years)† & $56.1(15.6)$ & $57.6(14.8)$ & $52.8(16.6)$ & * \\
\hline Female $(\mathrm{n}(\%)) \ddagger$ & $260(68.6)$ & $181(70.2)$ & $79(65.3)$ & NS \\
\hline Disease duration (years)§ & $0.4(0.3$ to 0.7$)$ & $0.4(0.3$ to 0.7$)$ & $0.4(0.3$ to 0.6$)$ & NS \\
\hline ESR $(\mathrm{mm} / \mathrm{h}) \dagger$ & $31.8(22.8)$ & $36.1(23.2)$ & $22.8(19.0)$ & ** \\
\hline$C$ reactive protein $(\mathrm{mg} / \mathrm{dl}) \S$ & 15 (4 to 35$)$ & 18.5 (6.3 to 44$)$ & $6(2$ to 18$)$ & $* *$ \\
\hline DAS28 score & $4.8(1.3)$ & $5.2(1.2)$ & $4.1(1.2)$ & ** \\
\hline Sharp/van der Heijde score§ & $1(0$ to 6$)$ & $2(0$ to 6$)$ & $0(0$ to 4$)$ & * \\
\hline $\mathrm{HAQ}$ score & $1.0(0.8)$ & $1.2(0.8)$ & $0.8(0.6)$ & ** \\
\hline \multicolumn{5}{|c|}{$\begin{array}{l}\text { Value are mean (SD) or median (interquartile range). } \\
{ }^{*} p<0.01 ;{ }^{* *} p<0.001 \text {. } \\
\text { †Student's } t \text { test; } ¥ \chi^{2} \text { test; } \S \text { Mann-Whitney } U \text { test. }\end{array}$} \\
\hline
\end{tabular}

Sharp/van der Heijde score by at least 5 after two years follow up, ${ }^{23}$ those with smaller increases being classified as not progressive. Variables associated with the diagnosis of rheumatoid arthritis in the univariate analysis $(\mathrm{p}<0.10)$ were entered into the models as independent variables. The analyses were carried out with a backward logistic regression analysis in SPSS 11.5.

\section{RESULTS}

The basic characteristics of the ACF test, the anti-CCP test, and the IgM-RF test in the patients with established rheumatoid arthritis and the controls are given in table 1. At a specificity of $99 \%$, the sensitivities of the ACF test and the anti-CCP test were $67.8 \%$ and $71.1 \%$, respectively. At this specificity, the IgM-RF test was only $41.8 \%$ sensitive. As a control for ACF, IgG depleted fibrinogen was coated at $10 \mu \mathrm{g} /$ $\mathrm{ml}$ and the ELISA was carried out as described above. Subtracting the extinction obtained from the fibrinogen coat from that of citrullinated fibrinogen before calculation did not influence the specificity and sensitivity (data not shown). Cut off values of the tests at $99 \%$ specificity were $140 \mathrm{U} / \mathrm{ml}$ for ACF, $25 \mathrm{U} / \mathrm{ml}$ for anti-CCP, and $45 \mathrm{IU} / \mathrm{ml}$ for IgM-RF. To compare all tests at the same specificity, these high cut off values were chosen for further analysis in an early arthritis population.

Table 2 shows the baseline characteristics of that population. The group of patients with rheumatoid arthritis was significantly older $(\mathrm{p}<0.01)$, had higher mean ESR and $C$ reactive protein levels $(\mathrm{p}<0.001)$, a higher mean DAS $(\mathrm{p}<0.001)$, a higher median radiographic damage score $(\mathrm{p}<0.01)$, and a worse mean HAQ $(\mathrm{p}<0.001)$ than the group of patients with undifferentiated arthritis.

The sensitivity, specificity, and PPV for the diagnosis of rheumatoid arthritis of the tests described are shown in table 3. Sensitivities varied between $44.6 \%$ and $57.8 \%$, and

Table 3 Sensitivity, specificity, and positive predictive value (PPV) of ACF, anti-CCP, and IgM-RF for the clinical diagnosis of rheumatoid arthritis in early arthritis

\begin{tabular}{lcll}
\hline & Sensitivity (\%) & Specificity (\%) & PPV (\%) \\
\hline Early arthritis $(n=379)$ & & & \\
$\operatorname{lgM}-\mathrm{RF} \geqslant 45$ & 44.6 & 96.7 & 96.6 \\
$\mathrm{ACF} \geqslant 140$ & 55.8 & 92.6 & 94.1 \\
Anti-CCP $\geqslant 25$ & 57.8 & 94.2 & 95.5 \\
& & & \\
& & \\
$\lg M-R F$ negative early arthritis $(n=260)$ & & \\
$\mathrm{ACF} \geqslant 140$ & 28.7 & 94.9 & 87.2 \\
Anti-CCP $\geqslant 25$ & 30.8 & 96.6 & 91.7 \\
\hline
\end{tabular}

ACF, antibodies to citrullinated human fibrinogen; $C C P$, cyclic citrullinated peptide; RF, rheumatoid factor; ROC, receiver operating characteristic. specificities between $92.6 \%$ and $96.7 \%$. About $30 \%$ of the IgM-RF negative early arthritis patients were positive for ACF or anti-CCP or both. The ACF and anti-CCP tests had a very high agreement in early arthritis. ACF and anti-CCP were single positive in 29 of 379 patients $(\kappa=0.84$, data not shown); 16 patients were single positive for anti-CCP $(81.3 \%$ rheumatoid arthritis) and 13 patients were single positive for ACF (61.5\% rheumatoid arthritis).

Complete two year follow up data were available from 296 of the 379 early arthritis patients (78.1\%). These patients used a median of one DMARD (range one to five) during the period of follow up; $62 \%$ of the patients used methotrexate. The reasons for loss to follow up were: non-compliance $(\mathrm{n}=31)$; discharge from the clinic because of remission $(\mathrm{n}=17)$; moving home $(\mathrm{n}=10)$; death $(\mathrm{n}=9)$; and miscellaneous reasons $(n=16)$. The group of patients lost to follow up had similar baseline characteristics as the group which completed the follow up, except for the median baseline Sharp/van der Heijde score which was higher in noncompleters than in completers $(6 v 1, \mathrm{p}<0.001)$. Also, the non-completers were less often positive for IgM-RF ( $18.1 \% \mathrm{v}$ $35.1 \%)$, anti-CCP $(25.6 \% \vee 45.1 \%)$, or ACF $(26.8 \% \vee 43.7 \%)$ $(\mathrm{p}<0.01$ for all tests $)$ than the completers.

In the univariate analysis, all baseline variables were significantly associated with the diagnosis of rheumatoid arthritis at one year $(\mathrm{p}<0.05$, data not shown). Variables predictive of the diagnosis of rheumatoid arthritis in the logistic regression analysis were anti-CCP, IgM-RF, ACF, DAS28, and VAS pain (table 4). Because of the very high agreement between the ACF test and the anti-CCP test, two alternative predictive models were calculated with the same independent variables, but one without anti-CCP and one without ACF (data not shown). In the model without antiCCP, the ACF test was the best predictor of diagnosis rheumatoid arthritis (odds ratio $(\mathrm{OR})=10.3 ; 95 \%$ confidence interval (CI), 3.9 to 26.7) and in the model without ACF, the anti-CCP predicted diagnosis rheumatoid arthritis best ( $\mathrm{OR}=10.6 ; 95 \% \mathrm{CI}, 4.1$ to 27.8 ).

Baseline variables with a significant association with radiographic progression at two years of follow up were ACF, anti-CCP, IgM-RF, ESR, C reactive protein, DAS28, HAQ, and the Sharp/van der Heijde score $(p<0.001$, data not shown). Variables predictive of radiographic progression in the logistic regression analysis were anti-CCP, ESR, and the Sharp/van der Heijde score at baseline, with anti-CCP as the best predictor $(\mathrm{OR}=14.8)$ (table 5$)$. The ACF test was removed by this model, owing to the very high agreement between the ACF test and the anti-CCP test. Thus a second model for predicting radiographic progression was calculated without anti-CCP as an independent variable (table 6). In this model, ACF, ESR, and the Sharp/van der Heijde score at baseline were most predictive of radiographic progression, with the ACF test as the best predictor $(\mathrm{OR}=12.1)$. 
Table 4 Results of logistic regression analysis of baseline variables to predict rheumatoid arthritis at one year in early arthritis

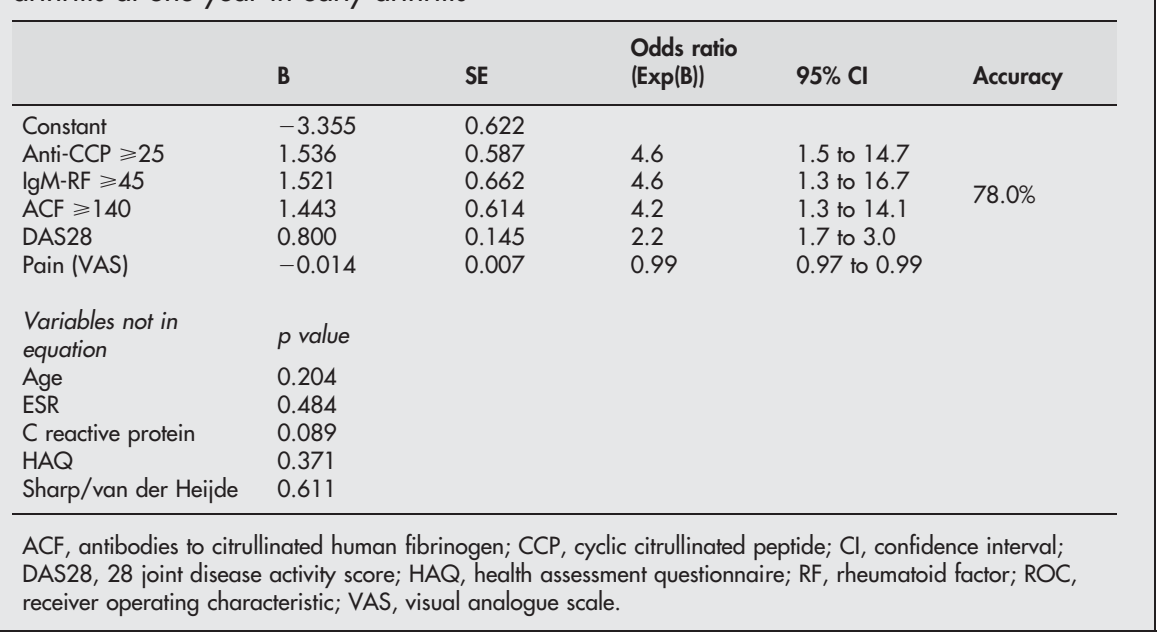

\section{DISCUSSION}

The diagnostic and prognostic value of antibodies directed against citrullinated fibrinogen was compared with that of the second generation anti-CCP test in an early arthritis cohort. For diagnosing rheumatoid arthritis, the ACF test was as sensitive as the second generation anti-CCP test and more sensitive than the IgM-RF test. About $30 \%$ of the IgM-RF negative patients with early arthritis were positive for the ACF test and therefore this test will be useful, especially in IgM-RF negative early arthritis patients.

Despite the higher sensitivity of the ACF test and the second generation anti-CCP test compared with the IgM-RF test for diagnosing rheumatoid arthritis, the specificity of the IgM-RF test was slightly higher. This reflects a small percentage of patients diagnosed with undifferentiated arthritis and having autoantibodies to citrullinated proteins. Such patients could eventually develop rheumatoid arthritis, as has been suggested by the high positive predictive value of anti-CCP in a prospective study of patients with early arthritis. ${ }^{24}$ In an earlier study in the same cohort, Jansen et al found a sensitivity of $42.6 \%$ and a specificity of $97.5 \%$ for the first generation anti-CCP test. ${ }^{10}$ In this early arthritis population, both the ACF test and the second generation anti-CCP test were more sensitive for the diagnosis rheumatoid arthritis. In an early rheumatoid population, Nogueira et al found a sensitivity for antibodies to citrullinated fibrinogen of $64.6 \%$ at $98.5 \%$ specificity, ${ }^{25}$ which is in line with the results of the present study. In multivariate analysis, we found that the anti-CCP test was the best predictor of the diagnosis rheumatoid arthritis, followed by the IgM-RF test and the ACF test (odds ratios around 4.5). Because of the high agreement of ACF and anti-CCP, it will not be useful to combine the two tests to predict the diagnosis of rheumatoid arthritis. Therefore, two other models were calculated with the same independent variables, but with only one of the two tests. In these models, baseline ACF and anti-CCP were similarly good predictors of the diagnosis rheumatoid arthritis one year later, with odds ratios of approximately 10.5 .

The prognostic value of the ACF test was evaluated with multivariate logistic regression analyses using two year follow up data. ACF was a good predictor of radiographic progression at the two year follow up, nearly as good as the anti-CCP test $(\mathrm{OR}=12.1 \vee \mathrm{l}$ 14.8). Compared with previous reports on the prognostic value of citrulline specific autoantibodies, including the first and second generation antiCCP test, an odds ratio of $12-14$ is remarkably high. ${ }^{811} 26-28$ The baseline characteristics of the non-completers were similar to those of the completers, except for the Sharp/van der Heijde score and the three antibody tests. The noncompleters had a higher median Sharp/van der Heijde score than the completers at baseline, although they were positive less often for IgM-RF, anti-CCP, and ACF. There may have been a coincidental selection of patients with a high Sharp/ van der Heijde score at baseline, and a subsequent mild course of the disease, resulting in remission and loss to follow

Table 5 Results of logistic regression analysis of baseline variables to predict radiographic progression at two years in early arthritis

\begin{tabular}{llllll}
\hline & B & SE & $\begin{array}{l}\text { Odds ratio } \\
\text { (Exp(B)) }\end{array}$ & 95\% Cl & Accuracy \\
\hline Constant & -3.468 & 0.438 & & & \\
Anti-CCP $\geqslant 25$ & 2.694 & 0.364 & 14.8 & 7.2 to 30.2 & $80.2 \%$ \\
Sharp/van der Heijde & 0.102 & 0.029 & 1.1 & 1.0 to 1.2 & \\
ESR & 0.024 & 0.007 & 1.02 & & \\
Variables not in equation & p value & & & & \\
lgM-RF $\geqslant 45$ & 0.376 & & & & \\
ACF $\geqslant 140$ & 0.099 & & & & \\
DAS28 & 0.412 & & & & \\
C reactive protein & 0.616 & & & & \\
HAQ & 0.481 & & & & \\
\hline
\end{tabular}

$\mathrm{ACF}$, antibodies to citrullinated human fibrinogen; $\mathrm{CCP}$, cyclic citrullinated peptide; $\mathrm{Cl}$, confidence interval; DAS28, 28 joint disease activity score; HAQ, health assessment questionnaire; RF, rheumatoid factor; ROC, receiver operating characteristic; VAS, visual analogue scale. 
Table 6 Results of logistic regression analysis of baseline variables (without anti-CCP) to predict radiographic progression at two years in early arthritis

\begin{tabular}{lllcll}
\hline & B & SE & $\begin{array}{l}\text { Odds ratio } \\
\text { (Exp(B)) }\end{array}$ & $95 \% \mathrm{Cl}$ & Accuracy \\
\hline Constant & -3.239 & 0.403 & & & \\
ACF $\geqslant 140$ & 2.494 & 0.343 & 12.1 & 6.2 to 23.7 & $81.7 \%$ \\
Sharp/van der Heijde & 0.090 & 0.029 & 1.1 & 1.0 to 1.2 & \\
ESR & 0.024 & 0.007 & 1.02 & 1.01 to 1.04 & \\
& & & & & \\
Variables not in equation & $p$ value & & & & \\
IgM-RF $\geqslant 45$ & 0.553 & & & & \\
DAS28 & 0.291 & & & & \\
C reactive protein & 0.955 & & & & \\
HAQ & 0.447 & & & & \\
\hline
\end{tabular}

ACF, antibodies to citrullinated human fibrinogen; $\mathrm{CCP}$, cyclic citrullinated peptide; $\mathrm{Cl}$, confidence interval; DAS28, 28 joint disease activity score; HAQ, health assessment questionnaire; RF, rheumatoid factor; ROC, receiver operating characteristic; VAS, visual analogue scale.

up. As the Sharp/van der Heijde score predicts radiographic progression, the selective loss to follow up may have led to an overestimation of the odds ratios of the anti-CCP test and the ACF test in predicting radiographic progression in our early arthritis population.

The results of this study underline the high disease specificity for antibodies to citrullinated proteins and peptides. However, the present data provide no explanation of how the antibody response develops in rheumatoid arthritis. There was no difference in sensitivity between the anti-CCP test and the ACF test in early arthritis and in established rheumatoid arthritis. In the vast majority of patients both ACF and anti-CCP were found. ACF and antiCCP were both single positive in $8 \%$ of EAC patients. The agreement between the tests is surprising as citrullinated fibrin (fibrinogen is the soluble precursor of fibrin) has been described as a physiological substrate for antibodies recognising citrulline containing epitopes. ${ }^{16}$ As has been shown for several other autoimmune disorders (reviewed by Doyle and Mamula $\left.{ }^{29}\right)$, antibodies might preferentially recognise a modified physiological target - that is, citrullinated fibrinearly in the disease. Later the antibody response could spread towards less restricted epitopes. ${ }^{30}$ Responses to uncitrullinated fibrinogen could be detected in our study population and were higher in patients than controls. However, they never reached the degree of positivity that was found with citrullinated fibrinogen. It is known that rheumatoid arthritis specific antibodies can be detected several years before the onset of clinical symptoms. ${ }^{31-33}$ Although the participants from the EAC in Amsterdam had a short disease duration at the time of testing for ACF and anti-CCP, differences between the two responses might be difficult to detect. The ACF response in patient samples taken before clinical signs of the disease could shed light on how the antibody response develops. Alternatively, other citrullinated proteins-for example, vimentin-might trigger the initial immune response in rheumatoid arthritis. ${ }^{5}$ Citrulline containing peptides, derived from the sequence of vimentin, have been shown to be efficiently presented by the rheumatoid arthritis associated HLA-DRB1*0401 MHC class II molecule to T cells in a transgenic mouse model. ${ }^{34}$ The data point towards an important role of citrulline as an anchor amino acid. Whether the overall sequence might be of less importance has to be elucidated in further studies.

In conclusion, the ACF test is useful for establishing the diagnosis of rheumatoid arthritis and is a good predictor of radiographic progression in early arthritis, comparable to the second generation anti-CCP test. Both tests are especially valuable in IgM-RF negative early arthritis.

\section{ACKNOWLEDGEMENTS}

We thank Anne-Marie Abrahams and Elleke de Wit-Taen for the collection of data at the early arthritis clinic, Margret de Koning and Irma Rensink for practical help, and Esmeralda Molenaar for collection of data on rheumatoid patients in remission.

\section{Authors' affiliations}

M M J Nielen, D van Schaardenburg, R J van de Stadt, Jan van Breemen Institute, Amsterdam, Netherlands

A $R$ van der Horst, D Hamann, Sanquin Diagnostics at CLB, Amsterdam I E van der Horst-Bruinsma, B A C Dijkmans, VU University Medical Centre, Amsterdam

L Aarden, Sanquin Research at CLB and Laboratory of Experimental Immunology, Academic Medical Centre, Amsterdam

\section{REFERENCES}

1 Arnett FC, Edworthy SM, Bloch DA, McShane DJ, Fries JF, Cooper NS, et al. The American Rheumatism Association 1987 revised criteria for the classification of rheumatoid arthritis. Arthritis Rheum 1988;31:315-24.

2 Saraux A, Berthelot JM, Chales G, Le Henaff C, Thorel JB, Hoang S, et al. Ability of the American College of Rheumatology 1987 criteria to predict rheumatoid arthritis in patients with early arthritis and classification of these patients two years later. Arthritis Rheum 2001;44:2485-91.

3 Schellekens GA, de Jong BA, van den Hoogen FH, van de Putte $L B$, van Venrooij WJ. Citrulline is an essential constituent of antigenic determinants recognized by rheumatoid arthritis-specific autoantibodies. J Clin Invest 1998;101:273-81.

4 Schellekens GA, Visser $H$, de Jong BA, van den Hoogen FH, Hazes JM, Breedveld FC, et al. The diagnostic properties of rheumatoid arthritis antibodies recognizing a cyclic citrullinated peptide. Arthritis Rheum 2000;43:155-63.

5 Zendman AJ, Vossenaar ER, van Venrooij WJ. Autoantibodies to citrullinated (poly)peptides: a key diagnostic and prognostic marker for rheumatoid arthritis. Autoimmunity 2004;37:295-9.

6 van Venrooij WJ, Hazes JM, Visser H. Anticitrullinated protein/peptide antibody and its role in the diagnosis and prognosis of early rheumatoid arthritis. Neth J Med 2002;60:383-8.

7 Goldbach-Mansky R, Lee J, McCoy A, Hoxworth J, Yarboro C, Smolen JS, et al. Rheumatoid arthritis associated autoantibodies in patients with synovitis of recent onset. Arthritis Res 2000;2:236-43

8 Kroot EJ, de Jong BA, van Leeuwen MA, Swinkels $H$, van den Hoogen FH, van't Hof $M$, et al. The prognostic value of anti-cyclic citrullinated peptide antibody in patients with recent-onset rheumatoid arthritis. Arthritis Rheum 2000;43:1831-5.

9 Visser H, le Cessie S, Vos K, Breedveld FC, Hazes JM. How to diagnose rheumatoid arthritis early: a prediction model for persistent (erosive) arthritis. Arthritis Rheum 2002:46:357-65.

10 Jansen $A L$, van $D H-B, I$, van Schaardenburg D, van de Stadt RJ, de Koning MH, Dijkmans BA. Rheumatoid factor and antibodies to cyclic citrullinated Peptide differentiate rheumatoid arthritis from undifferentiated polyarthritis in patients with early arthritis. J Rheumatol 2002;29:2074-6.

11 Vencovsky J, Machacek S, Sedova L, Kafkova J, Gatterova J, Pesakova V, et al. Autoantibodies can be prognostic markers of an erosive disease in early rheumatoid arthritis. Ann Rheum Dis 2003;62:427-30.

12 Smeets TJ, Vossenaar ER, Kraan MC, van Mansum WAM, Raats JM, van Venrooij WJ, et al. Expression of citrullin-containing antigens in RA synovium [abstract]. Arthritis Res, 2001;3(2 (P4)).

13 Baeten D, Peene I, Union A, Meheus L, Sebbag M, Serre G, et al. Specific presence of intracellular citrullinated proteins in rheumatoid arthritis synovium: relevance to antifilaggrin autoantibodies. Arthritis Rheum 2001;44:2255-62. 
14 Reparon-Schuijt CC, van Esch WJ, van Kooten C, Schellekens GA, de Jong BA, van Venrooij WJ, et al. Secretion of anti-citrulline-containing peptide antibody by $B$ lymphocytes in rheumatoid arthritis. Arthritis Rheum 2001:44:41-7.

15 Masson-Bessiere C, Sebbag M, Durieux JJ, Nogueira L, Vincent C, Girbal-

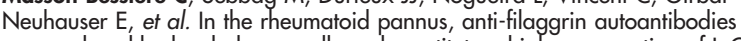
are produced by local plasma cells and constitute a higher proportion of $\lg G$ than in synovial fluid and serum. Clin Exp Immunol 2000; 1 19:544-52.

16 Masson-Bessiere C, Sebbag M, Girbal-Neuhauser E, Nogueira L, Vincent C Senshu $T$, et al. The major synovial targets of the rheumatoid arthritis-specific antifilaggrin autoantibodies are deiminated forms of the alpha- and betachains of fibrin. J Immunol 2001;166:4177-84.

17 Nogueira L, Sebbag M, Chapuy-Regaud S, Clavel C, Fournie B, Cantagrel A, et al. Autoantibodies to deiminated fibrinogen are the most efficient serological criterion for the diagnosis of rheumatoid arthritis [abstract] Arthritis Res, 2002;4(suppl 1).

18 Prevoo ML, van 't Hof MA, Kuper HH, van Leeuwen MA, van de Putte LB, van Riel PL. Modified disease activity scores that include twenty-eight-joint counts. Development and validation in a prospective longitudinal study of patients with rheumatoid arthritis. Arthritis Rheum 1995;38:44-8.

19 Fries JF, Spitz P, Kraines RG, Holman HR. Measurement of patient outcome in arthritis. Arthritis Rheum 1980;23:137-45.

20 van der Heijde DM van Leeuwen MA, van Riel PLCM, Koster AM, van 't Hof MA, van Rijswijk MH, et al. Biannual radiographic assessments of hands and feet in a three-year prospective followup of patients with early rheumatoid arthritis. Arthritis Rheum 1992;35:26-32.

21 Nogueira L, Sebbag M, Vincent C, Arnaud M, Fournie B, Cantagrel A, et al. Performance of two ELISAs for antifilaggrin autoantibodies, using either affinity purified or deiminated recombinant human filaggrin, in the diagnosis of rheumatoid arthritis. Ann Rheum Dis 2001;60:882-7.

22 Nissinen R, Paimela L, Julkunen H, Tienari PJ, Leirisalo-Repo M, Palosuo T, et al. Peptidylarginine deiminase, the arginine to citrulline converting enzyme, is frequently recognized by sera of patients with rheumatoid arthritis, systemic lupus erythematosus and primary Sjogren syndrome. Scand J Rheumatol 2003;32:337-42.

23 Bruynesteyn K, van der HD, Boers M, Saudan A, Peloso P, Paulus $H$, et al. Determination of the minimal clinically important difference in rheumatoid arthritis joint damage of the Sharp/van der Heijde and Larsen/Scott scoring methods by clinical experts and comparison with the smallest detectable difference. Arthritis Rheum 2002;46:913-20.
24 van Gaalen FA, Linn-Rasker SP, van Venrooij WJ, de Jong BA, Breedveld FC, Verweii $\mathrm{CL}$, et al. Autoantibodies to cyclic citrullinated peptides predict progression to rheumatoid arthritis in patients with undifferentiated arthritis: a prospective cohort study. Arthritis Rheum 2004;50:709-15.

25 Nogueira L, Chapuy-Regaud S, Constantin A, Clavel C, Sebbag M, Cantagrel $A$, et al. Autoantibodies to deiminated fibrinogen are the most efficient serological criterion for early rheumatoid arthritis diagnosis [abstract]. Arthritis Res Ther, 2003;5(suppl 1, (18)):S6.

26 Meyer O, Labarre C, Dougados M, Goupille P, Cantagrel A, Dubois A, et al. Anticitrullinated protein/peptide antibody assays in early rheumatoid arthritis for predicting five year radiographic damage. Ann Rheum Dis 2003;62:120-6.

27 Jansen LMA, van Schaardenburg D, van der Horst Bruinsma IE, van de Stadt RJ, de Koning MHMT, Dijkmans BAC. The predictive value of anti-cyclic citrullinated peptide antibodies in early arthritis. J Rheumatol 2003:30:1691-5.

28 Forslind K, Ahlmen M, Eberhardt K, Hafstrom I, Svensson B. Prediction of radiological outcome in early rheumatoid arthritis in clinical practice: role of antibodies to citrullinated peptides (anti-CCP). Ann Rheum Dis 2004:63:1090-5.

29 Doyle HA, Mamula MJ. Post-translational protein modifications in antigen recognition and autoimmunity. Trends Immunol 2001;22:443-9.

30 Monneaux F, Muller S. Epitope spreading in systemic lupus erythematosus: identification of triggering peptide sequences. Arthritis Rheum 2002;46:1430-8.

31 Aho K, Heliovaara M, Maatela J, Tuomi T, Palosuo T. Rheumatoid factors antedating clinical rheumatoid arthritis. J Rheumatol 1991;18:1282-4.

32 Rantapaa-Dahlqvist S, de Jong BA, Berglin E, Hallmans G, Wadell G, Stenlund $\mathrm{H}$, et al. Antibodies against cyclic citrullinated peptide and IgA rheumatoid factor predict the development of rheumatoid arthritis. Arthritis Rheum 2003;48:2741-9.

33 Nielen MM, van Schaardenburg D, Reesink HW, van de Stadt RJ, van der Horst-Bruinsma IE, de Koning MH, et al. Specific autoantibodies precede the symptoms of rheumatoid arthritis: a study of serial measurements in blood donors. Arthritis Rheum 2004;50:380-6.

34 Hill JA, Southwood S, Sette A, Jevnikar AM, Bell DA, Cairns E. The conversion of arginine to citrulline allows for a high-affinity peptide interaction with the rheumatoid arthritis-associated HLA-DRB 1*0401 MHC class II molecule. $J$ Immunol 2003;171:538-41. 